\title{
Mitral Regurgitant Jet Area to Left Atrial Area Ratio
}

National Cancer Institute

\section{Source}

National Cancer Institute. Mitral Regurgitant jet Area to Left Atrial Area Ratio. NCI

Thesaurus. Code C127577.

A relative measurement (ratio or percentage) of the mitral regurgitant jet area to left atrial area. 